九州大学学術情報リポジトリ

Kyushu University Institutional Repository

\title{
Precipitation Augmentation by A New Method of Cloud Seeding in Northern Kyushu (2)
}

Wakimizu, Kenji

Laboratory of Applied Meteorology, Division of Regional Environment Science, Department of Bioproduction Environmental Science, Faculty of Agriculture, Kyushu University

Nishiyama, Koji

Institute of Environmental systems, Faculty of Engineering, Kyushu University

Suzuki, Yoshinori

Laboratory of Applied Meteorology, Division of Regional Environment Science, Department of Bioproduction Environmental Science, Faculty of Agriculture, Kyushu University

Yoshikoshi, Hisashi

Laboratory of Applied Meteorology, Division of Regional Environment Science, Department of Bioproduction Environmental Science, Faculty of Agriculture, Kyushu University

他

https://doi.org/10.5109/24407

出版情報 : 九州大学大学院農学研究院紀要. 45 (2)，pp.565-575，2001-02-28. Kyushu University バージョン：

権利関係: 


\title{
Precipitation Augmentation by A New Method of Cloud Seeding in Northern Kyushu (2)
}

\author{
Kenji Wakimizu, Koji Nishiyama*, Yoshinori Suzuki, \\ Hisashi Yoshikoshi, and Norihiko Fukuta** \\ Laboratory of Applied Meteorology, Division of Regional Environment Science, \\ Department of Bioproduction Environmental Science, Faculty of Agriculture, \\ Kyushu University, Fukuoka 812-8581 \\ (Received October 31, 2000 and accepted November 10, 2000)
}

\begin{abstract}
In order to solve draught problems, a precipitation augmentation experiment based on a new airborne liquid carbon dioxide (LC) seeding at low level of supercooled convective clouds, was carried out in the northern Kyushu, February 2, 1999.

On this day, a cold air mass began to flow from the Siberia toward the Japanese Islands. This wind was very strong and cloud bands consisting of many cumuli ranged at constant interval above the Genkai Sea. Under the weather condition, three seedings were carried out. The second and third seedings resulted in rainfall of approximately 1.3 million tons during the lifetime of the seeded cumuli.

At the same time, unique, large mushroom-shaped radar echoes were discovered in the range height indicator (RHI) scans of Kyushu University (KU) radar for the plan position indicator (PPI) echoes near the maxima, which has never been observed among natural clouds.

Based on the observations, the optimum design of seeding operation for winter season is discussed.
\end{abstract}

\section{INTRODUCTION}

Effective modification of weather requires development of an effective seeding method, which consists of reproducible physical processes capable of causing the largest desirable changes. Only when this standard is used does the evaluation of operational results based on a statistical method become meaningful. If the physical effects were so clear that the significant cause and effect relationship could be recognized, the statistical method might even be bypassed. It is the purpose of this section to report such a result, which we have recently obtained, applying a new seeding method (Fukuta, 1996b, 1999).

In 1996, the seeding method using liquid carbon dioxide (LC) was developed by the University of Utah. Initially, this method was applied on the ground to the supercooled fog formed frequently in a winter season in Salt Lake City, USA (Fukuta, 1996b). As a result, the supercooled fog effectively disappeared in the area where the seeding was carried out. One of the reasons of the success is that the number of ice particles formed by LC seeding remains approximately constant after seeding as reported by Fukuta (1988). This means that ice particles can grow adequately to the precipitable size. In this study using small aircraft, the LC seeding method developed by Fukuta (1996b) was

\footnotetext{
* Institute of Environmental systems, Faculty of Engineering, Kyushu University, Fukuoka 812-8581

** Department of Meteorology, The University of Utha, Salt Lake City, Utah 84112, USA
} 
applied to the northern Kyushu in cooperation with Fukuoka Prefecture Government. As a result, the new seeding method succeeded in the formation of two artificial echoes. In this paper, based on analyses of the two artificial echoes, the possibility and optimum seeding design to increase precipitation are discussed.

\section{RETHIT AND FILAS OF ICE CRYSTALS THERMAL IN LIQUID CARBON DIOXIDE SEEDING}

A hypothesis based on horizontal penetration seeding of homogeneous ice nucleant at low level of a supercooled convective cloud was formulated accordingly (Fukuta, 1996, 1999). The total number of ice crystals with the nucleant remains essentially constant after the moment of the nucleation. The horizontally laid ice crystal thermal in the cloud, like cumulus convection, rolls up in the form of twin cylinders and turbulently spreads with the help of the buoyant motion caused by the heat of ice crystal growth or phase change (Fig. 1, Fukuta,1973). The supercooled cloud volume, slowly and continually taken into the ice thermal during the ascent, sustains the condition and time for crystal growth, the heat generation, and the buoyancy to a maximum extent in feedback (RETHIT). When the enlarging thermal reaches the temperature inversion, which often exists at the cloud top, the thermal spreads horizontally in an anvil shape, but the crystals there have already acquired sufficient size to fall through the supercooled cloud volume below, grow, and generate heat. The heating induces lifting of the underlying cloudy, as well as moist air, allowing additional condensation of moisture to increase the condensate mass and artificial precipitation (FILAS).

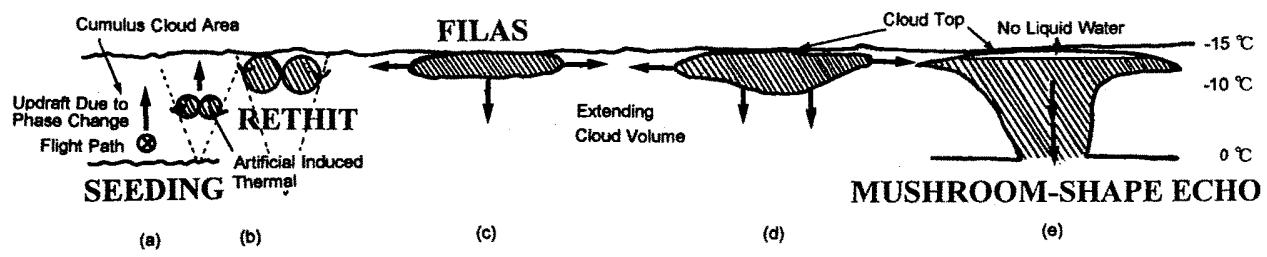

Fig. 1. The formation of artificial induced thermal by LC seeding and the development of horizontally moving and falling ice particles in the expanding artificial cloud volume (RETHIT, FILAS). ※ RETHIT: Roll-up Expantion of Twin Horizontal Ice Crystal Thermal. ※ FILAS: Falling-growth Induced Lateral Air Spreading.

\section{PROPERTIES OF LIQUID CARBON DIOXIDE AS SEEDING AGENT}

Some practical properties of LC have been presented by Fukuta (1996a). They are as follows;

(1) Low price (nearly $1 / 2$ of dry ice).

(2) Non-toxic and safe to the environment.

(3) Non-flammable and produces no asphyxiating fumes in the cockpit unlike dry ice.

(4) Convenient for long term strong. 
(5) A high pressure liquid for continuous and accurate discharging with its own vapor pressure $\left(52 \mathrm{~atm}\right.$ at $\left.15^{\circ} \mathrm{C}\right)$.

(6) LC has high ice nucleation efficiency due to strong cooling (Fukuta, 1965) and suitable characteristics for horizontal penetration seedings at low altitude.

\section{PLANNING OF SEEDING EXPERIMENT}

In a winter season, a cold anticyclone around the Siberia develops periodically. Then, the cold air starts to move toward the East China Sea and the Sea of Japan and the resultant wind flows strongly in these regions due to a large pressure difference between the cold continental anticyclone and cyclone around the Aleutian Islands. When the cold and dry air originated in the Siberia passes above the warm Tusima current flowing into the Sea of Japan, the atmosphere above the sea gradually becomes unstable because ample heat and vapor are supplied from the sea surface to the lower atmosphere. Then, cumuli generate above the sea and cloud bands consisting of many cumuli range at a constant interval as confirmed frequently by satellite images and the heavy snowfall is often brought in the mountainous areas close to the sea. This may mean that water resource supplied in a winter season originates in the Sea of Japan. For this reason, cumuli approaching to the north area of the Kyushu Island above the Genkai Sea with a seasonal wind were selected as the targets of the seeding.

\section{OBSERVATION}

The northwest area of Fig. 2 the Genkai Sea was selected as the experimental area of LC seeding in order not to disturb the commercial air routes. The seeding operation was the Kita Kyushu Airport located in the east of Fig. 2. X band radar of Kyushu University (KU) located at the center of the map was used to observe the movement and development of cumuli. The KU radar has spatial resolution of $1 \mathrm{~km} \times 1 \mathrm{~km}$ with wavelength of $3.2 \mathrm{~cm}$ in the relatively narrow area of $100 \mathrm{~km} \times 100 \mathrm{~km}$. The plan position indicator (PPI) and range height indicator (RHI) data, which represent a horizontal and vertical rainfall distribution, respectively, were recorded manually for several hours after seeding. Positions of the airplane and locations of seeding were determined by global positioning system (GPS) device. Height and air temperature at seeding locations were measured by the device equipped in the airplane.

\section{RESULT AND DISCUSSION PRECIPITATION FOR SEEDING EXPERIMENT}

The airborne seeding experiment using LC was carried out on February 2, 1999. On this day, it could be expected that supercooled cumuli suitable for seeding appeared above the Genkai Sea because the weather condition mentioned in the previous section had been forecasted (Fig. 3, 4). The intrusion of cold air into the northern Kyushu was confirmed by the fact that a seasonal wind was felt to be very strong at around 1000 JST. In this stage, execution of the seeding experiment was decided and our stuff went to the Kita Kyushu Airport and stood by for the experiment. From satellite images of 1100 to 1300 JST, many cloud bands were observed in the Sea of Japan and an area of clouds 


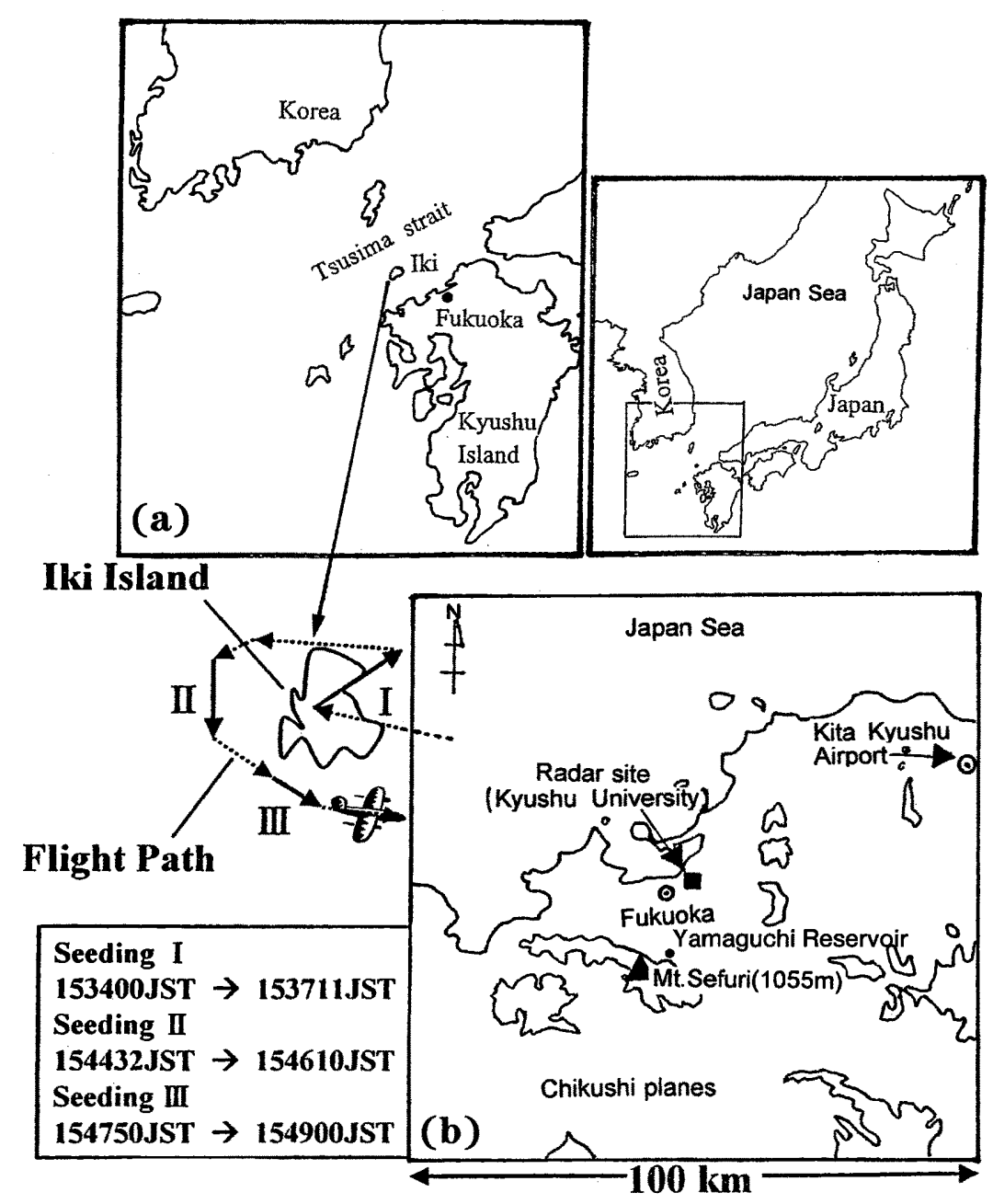

Fig. 2. (a) A map of the area where the seeding experiment was performed.

(b) Flight path and seeding duration of the airplane.

extended gradually toward the Tushima Channel.

The new method of penetration seeding was tested in supercooled convective clouds using LC (Fukuta, 1965) near Iki Island, in the northern Kyushu, Japan at the outbreak of cold Siberian air above the warm Tsushima current on 2 February 1999. Three seedings were carried out at $-4{ }^{\circ} \mathrm{C}$ level in clouds $2 \mathrm{~km}$ thick at upwind sites at Kyushu University $(\mathrm{KU})$, Fukuoka, with LC discharging rate of $6 \mathrm{~g} / \mathrm{s}$ and the position of seeding aircraft being marked by GPS. Cloud base was observed at $1.3 \mathrm{~km},-2{ }^{\circ} \mathrm{C}$ altitude, and a strong temperature inversion at $4 \mathrm{~km}$ (Fig. 5,6). Seeding effects were monitored by the 


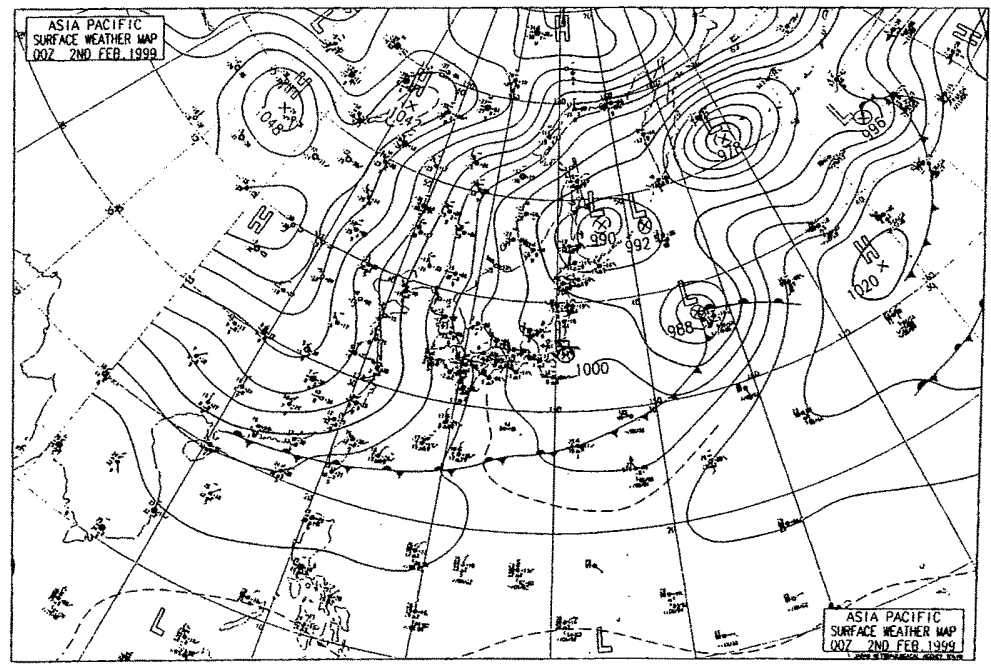

(a)

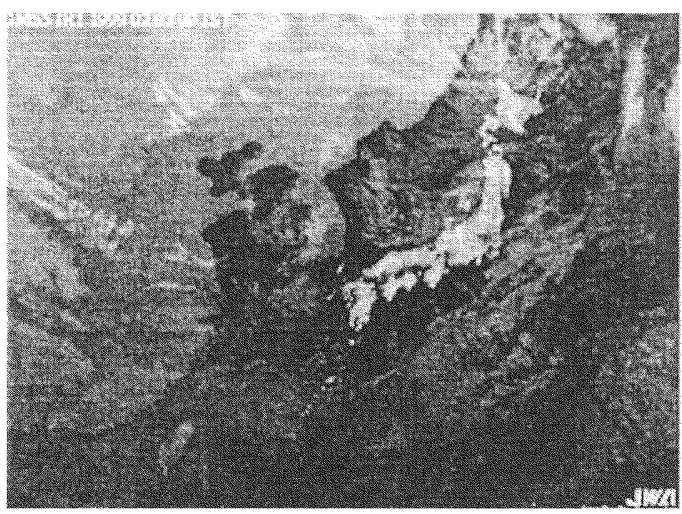

(b)

Fig. 3. (a) Surface weather chart at 0900 JST on 2 February 1999. (b) A GMS visible cloud image at 0900 JST on 2 February 1999.

operational PPI 5-cm radar system of the Japanese Meteorological Agency (JMA) and by KU PPI and RHI 3.2-cm radar, with the help of sounding and rain gauge network data. Seeding I apparently went through shallow clouds and failed to develop echoes. The echo of seeding II became visible in $30 \mathrm{~min}$, distinguished from the adjacent natural ones in 45 min, and reached a maximum of $17-\mathrm{km}$ diameter and $200-\mathrm{km}^{2}$ area in $1.5 \mathrm{~h}$, and precipitated out completely in $2 \mathrm{~h}$, while moving with a wind, $66 \mathrm{~km} / \mathrm{h}$, changing from $280^{\circ}$ to $293^{\circ}$. The echo of seeding III behaved similarly, reaching about the same maximum in $70 \mathrm{~min}$ and precipitated out in $2 \mathrm{~h} 10 \mathrm{~min}$. At the Yamaguchi Reservoir in the passage of 

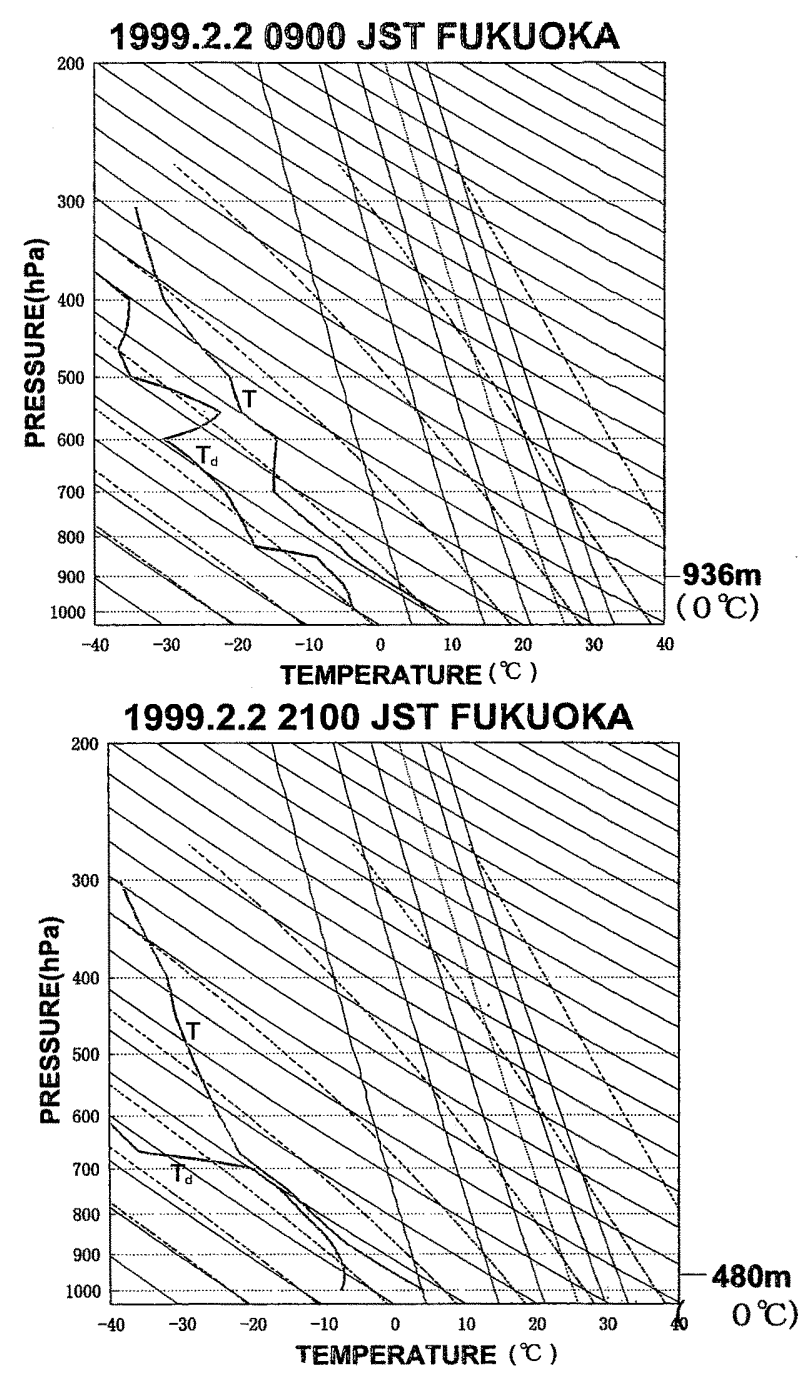

Fig. 4. Profiles of temperature $(T)$ and dew point temperature (Td) over Fukuoka at 0900 JST and 2100 JST on 2 February, 1999.

seeding III echo, the rain gauge recorded $1 \mathrm{~mm}$ of precipitation in $17 \mathrm{~min}$, corresponding to an intensity of $4 \mathrm{mmh}^{-1}$ (Fig. 7).

Unique, large mushroom-shaped radar echoes were discovered in RHI scans of KU radar for the PPI echoes near the maxima (Fig. 8), which has never been observed among natural clouds. However, such a cloud shape is commonly seen with the naked eye when a strongly convective cloud hits an inversion. Ice crystals in the cloud do not grow in suf- 
Kyushu (2)

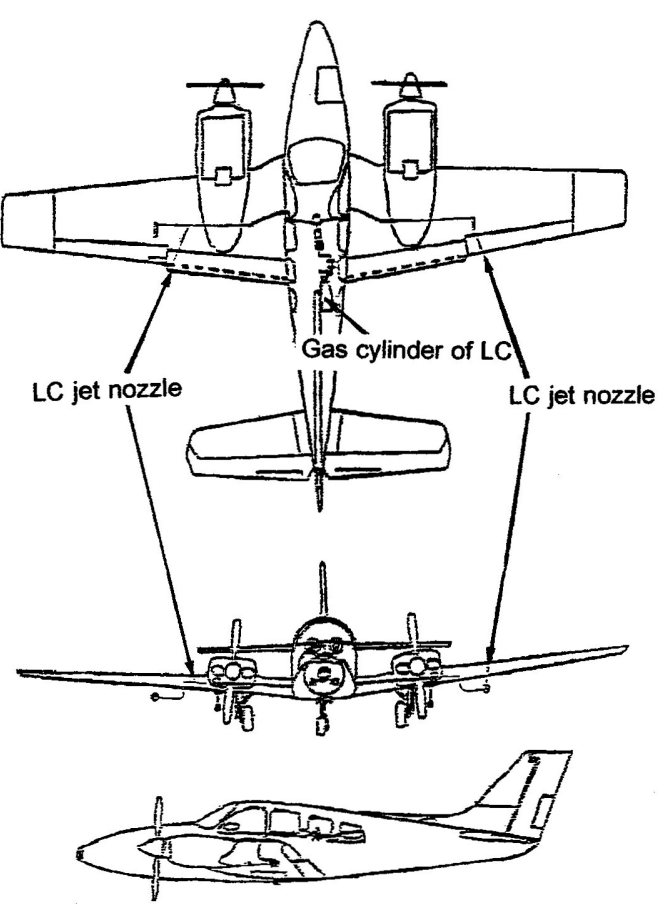

(a)

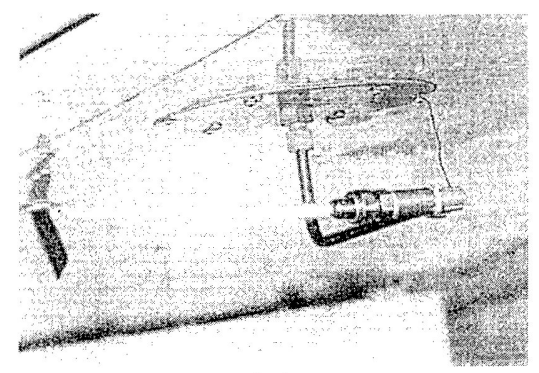

(b)

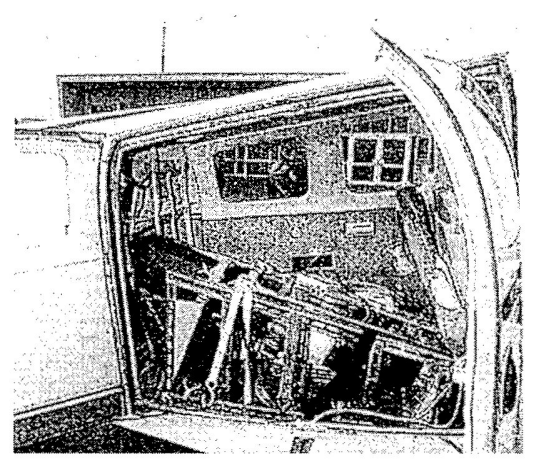

(c)

Fig. 5. Airframe installation situation. (a) Rough sketch of aircraft used to experiment on artificial rainfall. (b) Liquid carbon dioxide (LC) jetted from nozzle under wing. (c) Liquid carbon dioxide (LC) gas cylinder installed by airframe.

Cloud Top Temperature $-10^{\circ} \mathrm{C}$

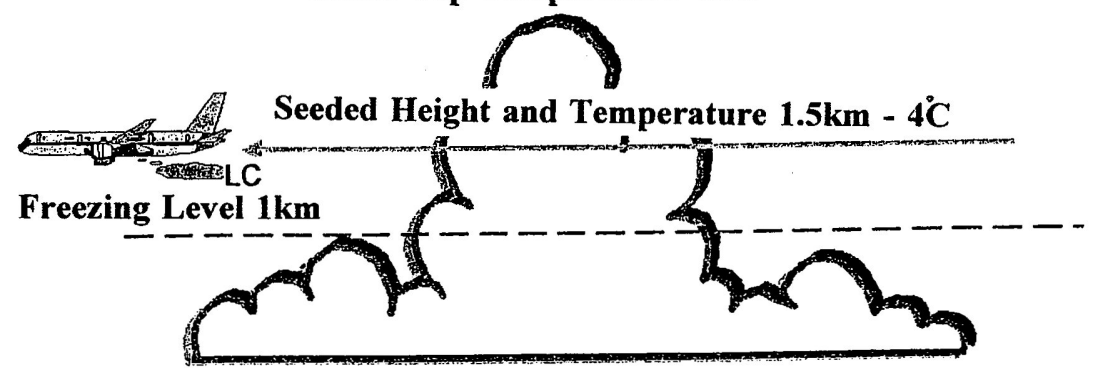

Seeding Rate 6g/s

Fig. 6. Liquid carbon dioxide (LC) scatter situation. 

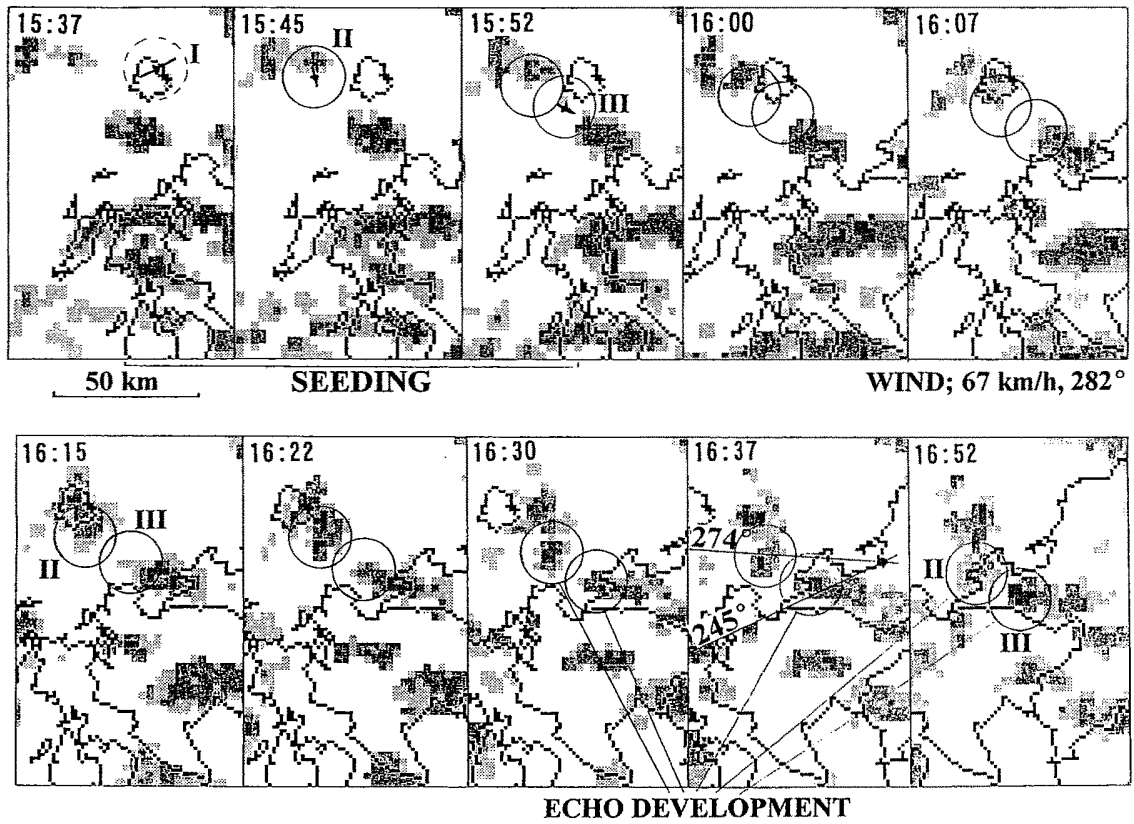

ECHO INDUCTION IN II SIDE

WIND; $67 \mathrm{~km} / \mathrm{h}, 282^{\circ}$
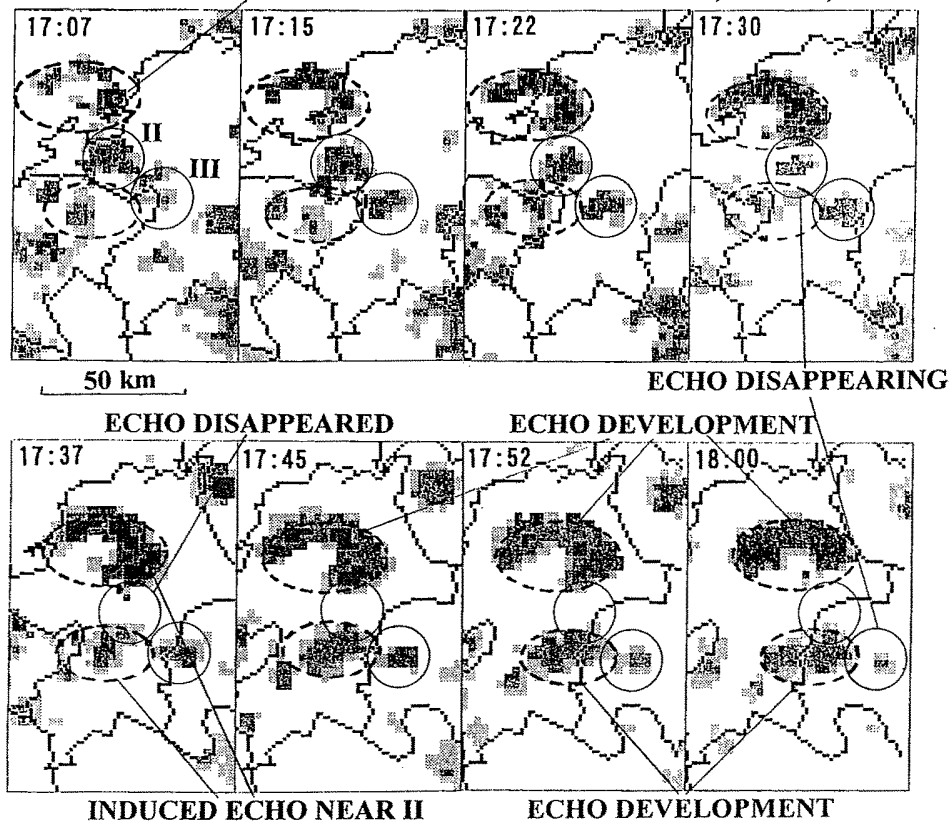

Fig. 7. Evolution of echoes in the seeded and surrounding clouds on JMA composite, $5 \mathrm{~cm}$ PPI radar system with the average beam altitude at $2 \mathrm{~km}$ on 2 February 1999, Fukuoka. Circles describe the assessed positions of original seeded air parcels, with the second and third seedings marked by II and III. 


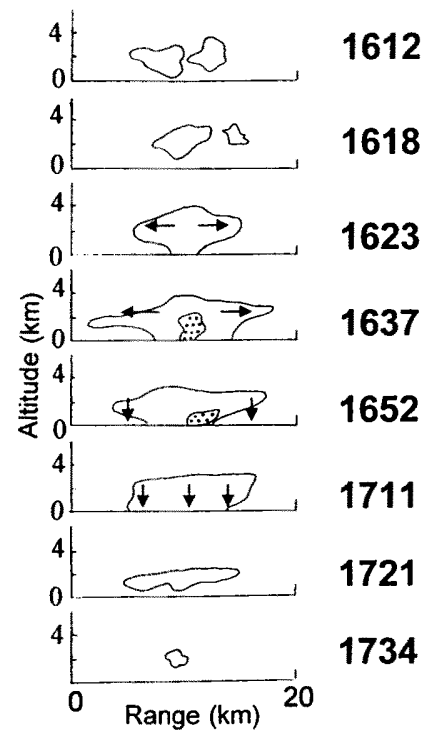

(a) RHI radar echoes
Kyushu (2)

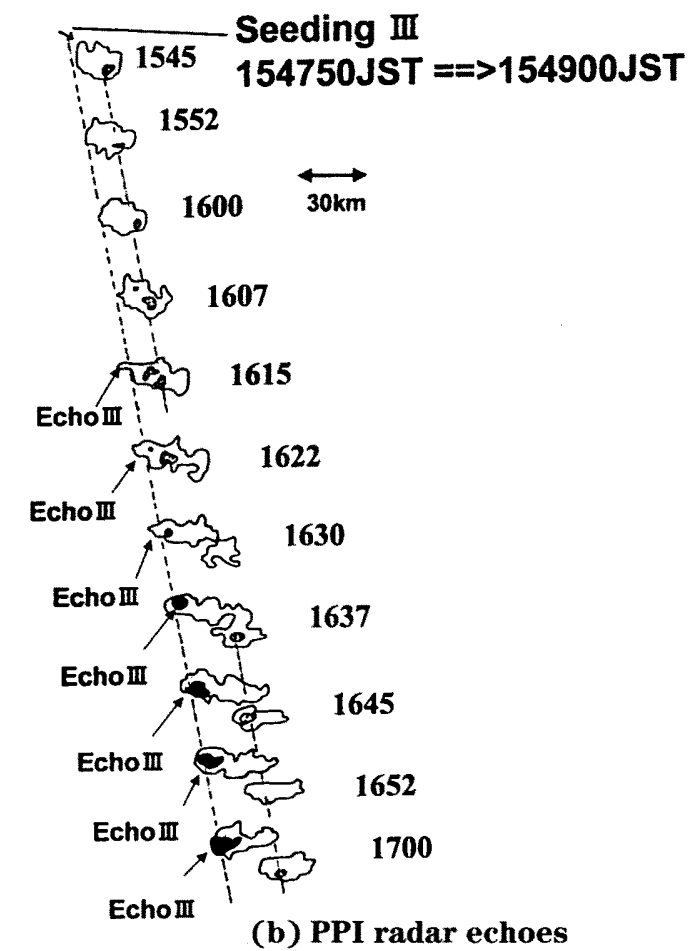

Fig. 8. The movement of the artificial radar echoes (PPI and RHI) formed by LC seeding, February 2, 1999, in the northern Kyushu. Mushroom-shaped radar echoes were discovered in RHI scans at 1637JST and 1652JST.

ficient number and size due to the lack of time required to show the characteristic shape on radar. The discovery of the uniquely shaped RHI echoes proves that the sustained ice crystal growth in the new seeding hypothesis indeed occurs in the dynamically expanding artificial ice thermal that leads to spontaneous precipitation. Precipitation from seeding III echo for $1.2 \mathrm{~min}$, 420-gLC discharging, and estimated by the rain gauge data, amounted to $10^{9} \mathrm{~kg}$ with the help of the released heat of phase change.

For the purpose of bringing more precipitation around the Sefuri mountain range, LC seeding should be carried out against many cumuli around 20 to $30 \mathrm{~km}$ from the coastline for several hours considering the time interval of approximately 20 min required for the growth from the first small ice particle to the precipitable size. By this method, if LC seeding stimulates inactive 20 cumuli for several hours, water resource of approximately 10 million tons may be brought down around the Sefuri mountain area assuming the total rainfall of average 0.5 million tons per artificial echo, which necessarily depends on weather and cloud condition.

\section{RESULTS AND DISCUSSION}

The optimized LC seeding method has been described by two processes; The first 


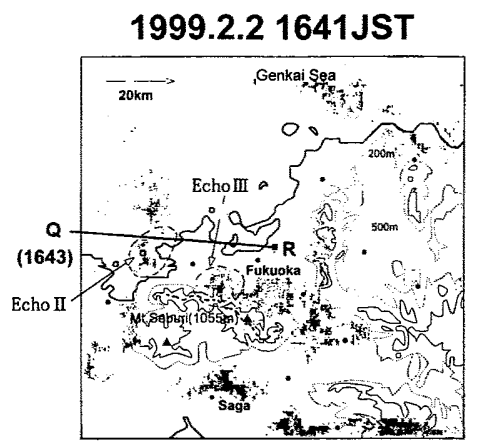

1999.2.2 1643JST

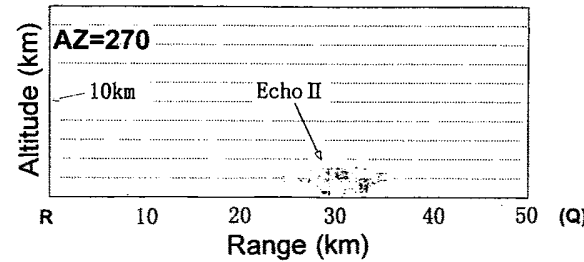

1999.2.2 1636JST

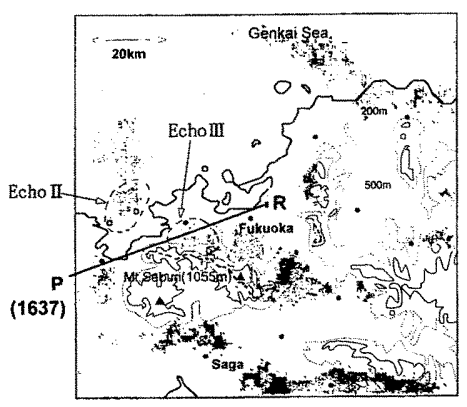

1999.2.2 1637JST

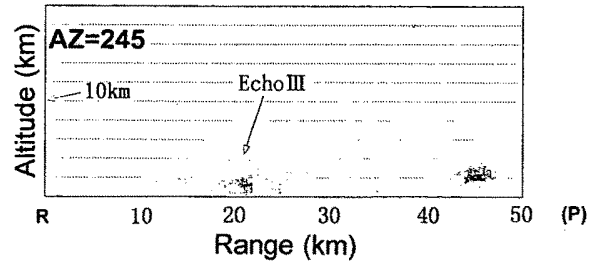

Fig. 9. Mushroom-shaped RHI echoes recorded on KU radar for seedings II and III at the time of their development: for II at $\mathrm{AZ}=270^{\circ}, 1643 \mathrm{JST}, 57 \mathrm{~min}$ after $98 \mathrm{~s}$ seeding, and for III at $\mathrm{AZ}=245^{\circ}, 1637$ JST, 48 min after $70 \mathrm{~s}$ seeding,respectively.

process is related to the rising of formed ice thermal caused by seeding which is called RETHIT process. And the second process is concerned to the spreading and falling down of the ice thermal which is called FILAS process.

1) The new method of penetration seeding was tested in supercooled convective clouds using liquid carbon dioxide (LC) (Fukuta, 1965) near Iki Island, in the northern Kyushu, Japan, when it was the outbreak of cold Siberian air above the warm Tsushima current on 2 February 1999. According to RETHIT and FILAS processes, unique, large mushroom-shaped radar echoes were discovered in RHI scans of Kyushu University radar for the PPI echoes near the maxima, which has never been observed among natural clouds. However, such a cloud shape is commonly seen with the naked eye when a strongly convective cloud hits an inversion. Ice crystals in the cloud do not grow in sufficient number and size due to the lack of time required to show the characteristic shape on radar. The discovery of the uniquely shaped RHI echoes proves that the sustained ice crystal growth in the new seeding hypothesis indeed occurs in the dynamically expanding artificial ice thermal that leads to spontaneous precipitation.

2) Precipitation from seeding III echo for $1.2 \mathrm{~min}, 420-\mathrm{g} \mathrm{LC}$ discharging, and estimated by the rain gauge data, amounted to $10^{\circ} \mathrm{kg}$ with the help of the released heat of phase change.

3) From these observational facts and the estimation of rainfall, the optimum seeding operation to be applicable for winter season was designed. If LC seeding stimulates inactive twenty cumuli around 20 to $30 \mathrm{~km}$ from the coastline for several hours, water 
resource of approximately 10 million tons may be brought down around the Sebri mountain area assuming the total rainfall of average 0.5 million tons per artificial echo.

\section{ACKNOWLEDGEMENTS}

Finally, I express special thanks to the members of the Artificial Rainmaking Committee, the Fukuoka Prefectural Government.

\section{REFERENCES}

Fukuta, N., 1965: Production of ice crystals in air by a pressure-pack method. J. Appl. Meteorol. 4, $454-456$.

Fukuta, N., 1972: Metaldehyde seeding in summer-time cumuli. J. Rech. Atmos., "Memorial Henri Dessens" No. 1-2-3, 165-174.

Fukuta, N., 1973: Thermodynamics of cloud glaciation. J. Atmos. Sci. 30, 1645-1649.

Fukuta, N., 1981: Side-skim seeding for convective cloud modification. J. Wea. Mod., 13, 188-192.

Fukuta, N., 1988: The maximum rate of homogeneous ice nucleant in air by cooling. Proc. 12th Intl. Conf. on Nucleation and Atmos. Aerosols, Vienna, Springer-Verlag, 504-507.

Fukuta, N., 1996a: Project mountain valley sunshine-progress in science and technology. J. Appl. Meteor., 35, 1483-1493.

Fukuta, N., 1996b: Low level penetration seeding with homogeneous ice nucleation for optimization of the induced microphysics-dynamics interactions. Preprints, Proc.13th 0 Conf. on Planned and Inadvert. Wea. Mod., Atlanta, Amer. Meteor. Soc., 164-171.

Fukuta, N., 1998: Conceptual structure for optimal utilization of phase change energy in RETHIT-FILAS feedback seeding mechanism. 14th Conf. on Planned and Inadvert Wea. Mod., 17-21 August 1998, Everett, WA, Preprints, 618-621.

Fukuta, N., 1999: Feedbacked utilization of phase change energy for lifting, turbulence generation and spreading of seeding ice thermal and optimization of the seeding effect. Preprints, 7th WMO Scientific Conf. on Wea. Mod., Chiang Mai. 363-366.

Wakimizu, K., K. Nishiyama, Y. Suzuki, H. Yoshikoshi, and N. Fukuta, 2000: Precipitation augmentation by a new method of cloud seeding in Northern Kyushu. Proceedings of the International Symposium on Lowland Tecnology, Saga University, October 2000, 323-330. 